\title{
Economic Dispatch of Electric Energy Storage with Multi-service Provision
}

\author{
You, Shi; Træholt, Chresten; Poulsen, Bjarne
}

Published in:

IPEC, 2010 Conference Proceedings

Link to article, DOI:

10.1109/IPECON.2010.5697052

Publication date:

2011

Document Version

Publisher's PDF, also known as Version of record

Link back to DTU Orbit

Citation $(A P A)$ :

You, S., Træholt, C., \& Poulsen, B. (2011). Economic Dispatch of Electric Energy Storage with Multi-service Provision. In IPEC, 2010 Conference Proceedings IEEE. https://doi.org/10.1109/IPECON.2010.5697052

\section{General rights}

Copyright and moral rights for the publications made accessible in the public portal are retained by the authors and/or other copyright owners and it is a condition of accessing publications that users recognise and abide by the legal requirements associated with these rights.

- Users may download and print one copy of any publication from the public portal for the purpose of private study or research.

- You may not further distribute the material or use it for any profit-making activity or commercial gain

- You may freely distribute the URL identifying the publication in the public portal 


\section{Economic Dispatch of Electric Energy Storage with Multi-service Provision}

\author{
Shi You, Chresten Træholt \\ Dept. of Electrical Engineering \\ Technical University of Denmark \\ 2800 Kgs. Lyngby, Denmark \\ \{sy,ctr\}@elektro.dtu.dk
}

\author{
Bjarne Poulsen \\ Dept. of Informatics and Mathematical \\ Technical University of Denmark \\ 2800 Kgs. Lyngby, Denmark \\ bjp@imm.dtu.dk
}

\begin{abstract}
This paper develops a generic optimization model that explores the difficulty met by Electric Energy Storage (EES) systems when economic dispatch for multiple-service provision is requested. Such a model is further used to investigate the economic performance of an EES system which meets the 10minute balancing requirement and hourly load shifting opportunities in the Western Electricity Coordinating Council (WECC) area for a 2030 load scenario. Piecewise linear equations are used to represent the cost function of varying load. The results show that when EES is economically dispatched, to achieve multiple value streams could result in more saving than to provide single service.
\end{abstract} service

Keywords-Eelectric Energy Storage; economic dispatch;multi-

\section{INTRODUCTION}

By concerting electric energy into other forms, such as chemical, kinetic of potential energy, the electricity can be stored and drawn upon at a later time to perform useful operation. Based on these principles, advanced electric energy storage (EES) technologies are emerging as a potential resource to support the integration of intermittent Renewable Energy Resources (RES) and to provide cost-effective and reliable grid operation.

Pumped Hydro Storage (PHS) is the most widespread utility-scale EES with good performance characteristics (good roundtrip efficiency $55 \%-85 \%$, low operation cost around $10000 € / \mathrm{MW} /$ year and long life-time about 50 years) in use today. The response time of PHD is on a one minute scale if the turbine is standing still and 10 second if the turbine is initially spinning- allows PHS plants to deliver multiple services such as peak shaving, load leveling, load following, spinning reserve and more [1]. Another utility-scale EES technology that is currently available is the Compressed Air Energy Storage (CAES). In such a storage system, excess electricity is converted to compressed air and stored in a reservoir. In the mode of discharging, the air is released, heated via combustion together with fuel and is finally passed through a turbine. One example of CAES is a $290 \mathrm{MW} / 3 \mathrm{~h}$ plant in Huntorf, Germany. Among other services, the Huntorf CAES has also been used to balance wind power generation [2]. Unlike PES and CAES with typical capacity above tens of MW, other EES technologies such as Batteries, Supper Magnetic Energy Storage (SMES), Hydrogen Fuel Cell Storage System (HFCSS)

This work was supported by the Technical University of Denmark (DTU) and collaborative partner: Pacific Northwest National Laboratory (PNNL). and Flywheels may be sized from several $\mathrm{kW}$ to hundreds of MW, which makes such technologies available for both utilities and their customers [3]. For small-scale EES applications like Electric Vehicles (EV), the EV owners only contributed to eliminate $\mathrm{CO} 2$ emissions when driving but also may benefit from the volatility of electricity prices by charging smartly. If numerous small-scale EES can be further efficiently aggregated into a Virtual Power Plant (VPP) like framework [4], providing value-added services to grid operation may be envisioned.

Many previous studies have presented optimal operation schemes for EES in hybrid applications, such as wind power with EES [5-6] and PV with battery [7] ect, in order to smooth out the intermittent nature of some RES. In [8-9], optimal generation schedules are developed for EES to provide specific services like load leveling and peak shaving. However, as the EES is able to perform multiple grid services at the same time, there is a need to develop efficient dispatch strategies which consider multi-service provision. Such strategies should run the EES at the maximum profit to reliably provide various services, recognizing the operational limits of the EES and services' requirements e.g. cycle time limit and capacity limit as well as the associated value for every service. This paper presents a generic deterministic optimization model of the EES that deals with this challenge. Main outputs of this model is an optimal operational plan for the EES charging/discharging as functions of every service requirements. When a long term study is carried out, the resulted economic performance of the EES is also useful to evaluate the outcome of different service combinations.

The paper is organized as follows: in Section II, the problem of economic dispatch of the EES with multi-service provision is formulated. In Section III, this model is used to investigate the economic performance of an EES system which meets the 10-minute balancing requirement and hourly load shifting opportunities in the Western Electricity Coordinating Council (WECC) area for a 2030 load scenario. A comparison is done between the economic benefits of providing the combined service versus a mere load shifting. Section IV concludes the paper.

\section{MODELING THE EES SYSTEM}

Generally speaking, the EES is a memory device and it becomes economical when marginal cost of electricity varies more than the accumulated costs of storing and retrieving, 
including the energy lost in the process. From the system operator point of view, the aim of using EES in power system operation is to reduce the societal cost while meeting the system requirements. In other words, the profit, which can be represented by the cost difference between operating a power system without the EES and with the EES, has to be maximized. When multi-service provision is at request, the profit is the sum of the profit resulted from providing each service by the EES. This problem can be formulated as an optimization problem.

Assuming EES provides $N$ types of services simultaneously, and $t_{i}$ with $i \in 1 \ldots N$ represents the time cycle for service $i$, which may vary from seconds to days. In order to synchronize the time clock for different services, $t^{\prime}$ is used to denote the greatest common divider of $t_{i}$. For instance, if EES provides hourly load shifting and 10-minute balancing service at the same time, $t^{\prime}$ is found as 10 minutes. For all time steps $t^{\prime} \in 0,1 \ldots T$, the EES must meet power balance and energy balance which are modeled by (1) and (2) respectively.

$$
\begin{aligned}
& P\left(t^{\prime}\right)=\sum_{i=1}^{N} P_{i}\left(t^{\prime}\right) \\
& E\left(t^{\prime}+1\right)=E\left(t^{\prime}\right)+P\left(t^{\prime}\right) \cdot \Delta t \cdot \eta+l(\Delta t) \\
& \text { where } \eta= \begin{cases}\eta_{c} & \text { if } P\left(t^{\prime}\right) \geq 0 \\
1 / \eta_{d} & \text { if } P\left(t^{\prime}\right)<0\end{cases}
\end{aligned}
$$

In (1), variable $P\left(t^{\prime}\right)$ states the aggregated power charged/discharged by the EES at time step $t^{\prime}$, and $P_{i}\left(t^{\prime}\right)$ describes power provided by the EES to meet the individual power requirement of service $i$ at that particular moment. Positive values of $P_{i}\left(t^{\prime}\right)$ represent the EES being charged to meet the requirement of service $i$ and negative values indicate the EES being discharged. However, the symbol of $P\left(t^{\prime}\right)$ determines the final charging/discharging status of the EES. In (2), the non-negative variable $E\left(t^{\prime}\right)$ represents the energy stored by EES at the beginning of time step $t^{\prime}$ and $\Delta t$ states the length of $t^{\prime}$. The variable $\eta$, as indicated in (3), represents the function of charging/discharging efficiency $\eta_{c}$ and $\eta_{d}$. When $t^{\prime}=0, E(0)$ therefore represents the initial energy stored by the EES. $l(\Delta t)$ represents the internal energy loss during energy storing over $\Delta t$. For different EES technologies, function $l(\Delta t)$ may vary quite a lot. EES technologies like underground pumped hydro systems display very low loss, since they are designed to be isolated from the outside. In opposite pumped hydro systems with its unsheltered reservoirs and extreme weather conditions may display a high internal loss. However, if the cycle time for the requested power system service is relatively short, the internal energy loss for advanced EES technologies will be relatively low and thus can be ignored.

The other constraints for modeling an EES include the power capacity limit and energy capacity limit which appears following in (4)-(6).

$$
\begin{aligned}
& P\left(t^{\prime}\right) \leq P_{c \max } \quad \text { if } P\left(t^{\prime}\right) \geq 0 \\
& \left|P\left(t^{\prime}\right)\right| \leq P_{d \max } \quad \text { if } P\left(t^{\prime}\right)<0 \\
& E_{\min } \leq E\left(t^{\prime}\right) \leq E_{\max }
\end{aligned}
$$

where $P_{c \max }, P_{d \max }, E_{\min }$ and $E_{\max }$ represent the maximum power capacities for the EES charging and discharging and the minimum and maximum energy storage level respectively.

As mentioned before, the objective function is to maximize the profit of using EES to provide requested services over a certain time period. This function is expressed as

$$
\text { MaxSaving }=\sum_{i=n}^{N} \sum_{t^{\prime}=0}^{T} \operatorname{Cost}_{\theta e s}\left(i, t^{\prime}\right)-\sum_{i=n}^{N} \sum_{t^{\prime}=0}^{T} \operatorname{Cost}_{n o n-\varepsilon s s}\left(i, t^{\prime}\right)
$$

where $\operatorname{Cost}_{\text {ees }}\left(i, t^{\prime}\right)$ is the cost for providing the requested service $i$ during time period $t^{\prime}$ using a power system with the EES and $\operatorname{Cost}_{\text {non-ees }}\left(i, t^{\prime}\right)$ represents the corresponding cost for providing requested services using resources in the original power system. As the cost for providing different services are always valued in different ways, such as capacity pricing, energy pricing and so forth, the objective function may vary from case to case. Depending on how the cost function of each service provision is formulated, the EES model could be either linear or non-linear which results in different degree of complexities and accuracies of solving this optimization problem.

\section{CASE STUDY}

In this case study, the aforementioned optimization model is applied to investigate the economic performance of an EES system which meets the 10-minute balancing requirement and hourly load shifting opportunities in the Western Electricity Coordinating Council (WECC) area for a 2030 load scenario. The WECC region covers 1.8 million square miles, all or part of 14 states, two Canadian provinces and a portion of Mexico. The 2030 load scenario of the WECC region predicated by Pacific Northwest National Laboratory (PNNL) has a peak load of approximately $190 \mathrm{GW}$ and the values of 10 -minutes balancing signals between $\pm 15 \mathrm{GW}$ introduced by the future increase of wind power penetration. The EES system, which represents an aggregation of all kinds of EES like facilities deployed in the WECC region, is assumed to be with an energy capacity of $30 \mathrm{GWh}$ and a power capacity of $15 \mathrm{GW}$ for both charging and discharging in order to meet the required services. Further, a series of assumptions for the 2030 scenario are made as following:

a). The EES is the only balancing resource in this system therefore it has to exactly meet the 10-minute balancing requirement.

b). The power of the EES charged/discharged for load shifting is constant on an hourly basis.

c). The power of the EES charged/discharged for 10minute balancing holds constant within every 10 minutes.

d). Balancing signals are not affected by the change of load profile. The up balancing signals that indicate 
generation deficit are assumed to be positive; while the down balancing signals that indicate the generation surplus are assumed to be negative.

e). The EES system is lossless.

f). Hourly Locational Marginal Price (LMP) is used to calculate the system cost of load serving.

g). Hourly LMP is assumed to be a piecewise linear function of hourly load.

h). The balancing cost is calculated as the amount of energy used for balancing multiplying the balancing price. The balancing price is assumed to be $40 \$ / \mathrm{MW}$ hr constantly for both up and down balancing requirement during 2030 .

\section{A. Problem Reformulation}

\section{1) Constraints}

Based on Based on assumptions (a)-(d), the power balance of the EES could be easily established for every 10 minutes $(\Delta t)$ consecutively as shown in (8)-(10). In (8), variables $P_{\text {load }}\left(t^{\prime}\right)$ and $P_{\text {balancing }}\left(t^{\prime}\right)$ represents the power charged/discharged by the EES for shifting load and meeting balancing requirement respectively at time step $t^{\prime}$. In (9), at time step $t^{\prime}$, the original system load $P D_{\text {non-ees }}\left(t^{\prime}\right)$ is changed into $P D_{\text {ees }}\left(t^{\prime}\right)$ when the EES gets involved to perform load shifting. Equation (10) follows assumption (a), ensuring the up and down balancing signals $P B_{u p}\left(t^{\prime}\right)$ (positive) and $P B_{\text {down }}\left(t^{\prime}\right)$ (negative) are always met by discharging/charging EES.

$$
\begin{aligned}
& P\left(t^{\prime}\right)=P_{\text {load }}\left(t^{\prime}\right)+P_{\text {balancing }}\left(t^{\prime}\right) \\
& P D_{\text {ees }}\left(t^{\prime}\right)=P D_{\text {non-ees }}\left(t^{\prime}\right)-P_{\text {load }}\left(t^{\prime}\right) \\
& P_{\text {balancing }}\left(t^{\prime}\right)= \begin{cases}P B_{\text {up }}\left(t^{\prime}\right) & \text { if } P_{\text {balancing }}\left(t^{\prime}\right) \leq 0 \\
P B_{\text {down }}\left(t^{\prime}\right) \text { if } P_{\text {balancing }}\left(t^{\prime}\right)>0\end{cases}
\end{aligned}
$$

In terms of the energy balance of the EES as shown in (2), efficiencies for both charging and discharging become $100 \%$ under assumption (e); meanwhile the internal loss function $l(\Delta t)$ is neglected. Parameter values that constrain the power capacity and energy capacity of such EES are given in Table I.

TABLE I. LIST OF PARAMETER VALUES FOR THE EES SYSTEM

\begin{tabular}{|c|c|c|c|}
\hline$P_{c \max }$ & $15 \mathrm{GW}$ & $E_{\min }$ & 0 \\
\hline$P_{d \max }$ & $15 \mathrm{GW}$ & $E_{\max }$ & $30 \mathrm{GWh}$ \\
\hline
\end{tabular}

As the EES is the only balancing resource in this model, the initial energy stored in EES is assumed to be $10 \mathrm{GWh}$ for every optimization cycle in order to make sure the EES has enough energy to provide up-regulation services.

\section{2) Objective Function}

In this case study the cost functions expressed in (7) are comprised of two parts since the EES provides load shifting service and 10-minute balancing service together. While the costs for these two services have different formulations, it is explained separately in the following two sections 2-a and 2-b.

\section{2-a) Cost of Meeting the Load}

Generally the cost of meeting a certain load profile by a specific generation technology is dependent on the associated cost function. As WECC is an area containing various generation technologies, assumptions (f) are made to simplify this problem. This results in (11), which reflects the cost of meeting the hourly load profile.

$\operatorname{Cost}_{\text {load }}\left(t^{\prime}\right)=E D\left(t^{\prime}\right) \cdot \operatorname{LMP}\left(t^{\prime}\right)$

where $E D\left(t^{\prime}\right)$ represents the load at time step $t^{\prime}$ measured in MWh and $L M P\left(t^{\prime}\right)$ states a rate per MWh for that particular time step. Because $E D\left(t^{\prime}\right)$ changes when the EES performs load shifting as given in (9), a relationship between LMP and load has to be found to assess how much the LMP is affected by the involvement of EES. However, since LMP is theoretically calculated based on the system wide information rather than a single generation/load profile within that area, a loose coupling between the hourly LMP and load can only be found when the studied areas have adequate generation resources and play roles as energy exporters.

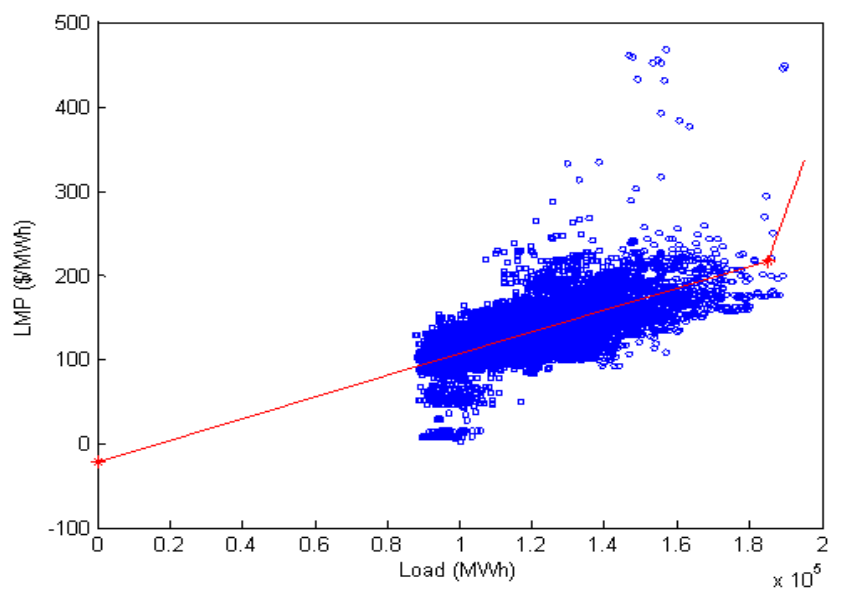

Figure 1. Representing the relationship between LMP and load for WECC with piecewise linear functions

As shown in Fig.1, the hourly LMP versus the hourly load profile predicted for WECC 2030 is indicted by the blue open dots. Such prediction is done by PNNL using PROMOD [10], a- state-of the-art production cost model based on extensive information of WECC. When the hourly load is between $90 \mathrm{GWh}$ and $185 \mathrm{GWh}$ the LMP increases gradually with increase of load. Once the hourly load exceeds $185 \mathrm{GWh}$, the associated LMP increases more steeply. In order to reduce the complexity, this trend is modeled by a piecewise linear function given as the red line in Fig.1, using a smooth curve fitting. And the LMP is therefore only load dependent. The piecewise linear function representing this relationship is given in (12). 
$L M P\left(t^{\prime}\right)=\left\{\begin{array}{l}0.0013 \cdot E D\left(t^{\prime}\right)-22.23 \text { if } E D\left(t^{\prime}\right) \leq 1.85 \times 10^{5} \\ 0.012 \cdot E D\left(t^{\prime}\right)-202235 \text { if } E D\left(t^{\prime}\right)>1.85 \times 10^{5}\end{array}\right.$

The cost of the system for meeting the load at $t^{\prime}$ before and after including the EES is given in (13) and (14) wherein the energy consumption $E D\left(t^{\prime}\right)$ is calculated as the product of the power consumption in each case and the time length $\Delta t$ with the unit of hour.

$$
\begin{aligned}
& \text { Costoad_nonees }_{\text {ton }}\left(t^{\prime}\right)=\frac{P D_{\text {non-ees }}\left(t^{\prime}\right) \cdot \Delta t \cdot L M P_{\text {non-ees }}\left(t^{\prime}\right)}{60} \\
& \operatorname{Cost}_{\text {load_ees }}\left(t^{\prime}\right)=\frac{P D_{e e s}\left(t^{\prime}\right) \cdot \Delta t \cdot L M P_{\text {ees }}\left(t^{\prime}\right)}{60}
\end{aligned}
$$

\section{2-b) Cost of balancing service}

The cost of providing balancing services at $t^{\prime}$ is expressed in (15), wherein $P B_{\text {balancing }}\left(t^{\prime}\right)$ states the balancing price in the unit of \$/MW-hr. Given assumption (h), $P B_{\text {balancing }}\left(t^{\prime}\right)$ remains 40\$/MW-hr for both up and down balancing services. When an EES is assumed to fully provide such 10-minute balancing service, the saving is equal to the cost when variable cost is the only concern.

$$
\operatorname{Cost}_{\text {balancing }}\left(t^{\prime}\right)=\frac{\left|P_{\text {balancing }}\left(t^{\prime}\right)\right| \cdot \Delta t \cdot P B_{\text {balancing }}\left(t^{\prime}\right)}{60}
$$

\section{2-c) Overall saving}

For all time-steps $t^{\prime} \in 0,1 \ldots T$, the overall saving is expressed in (16). The objective function is thus to maximize the overall saving. Because the hourly LMP is modeled as piecewise linear equations, (16) turns into a non-linear function The Matlab nonlinear optimization tool box [11] is used in this paper to find the optimal solutions for this problem.

Saving $=\sum_{t^{\prime}=0}^{t^{\prime}=T}$ Costbalancing $\left(t^{\prime}\right)+\sum_{t^{\prime}=0}^{t^{\prime}=T}\left(\right.$ Costoad_nonees $\left(^{\prime}\right)-$ Costoad_ees $\left.\left(t^{\prime}\right)\right)$

\section{B. Case Studies and Analysis}

The reformulated economic dispatch model is applied to investigate the economic performance of the simulated EES in both intraday analysis and annual analysis. In the Intraday analysis, the EES performances on two specific days of 2030: $1^{\text {st }}$ of January and $14^{\text {th }}$ of August are studied separately. The initial energy stored in the EES in both cases is assumed to be $10 \mathrm{GWh}$ in order to tackle the balancing requirement in the beginning of the day. The costs for the initial energy stored in EES in both cases are assumed to be 1.2 million \$, provided the LMP equals 120\$/MWh. Following that, annual economic performance of using EES to provide the referred two services is evaluated and further compared with the same EES providing load shifting service only.

\section{1) Case $1-1^{\text {st }}$ of January}

In Fig. 2, 10-minutes balancing signals are shown in the solid blue line. While in most time of the day, the balancing signals are up signals which require the EES to operate in discharging mode.

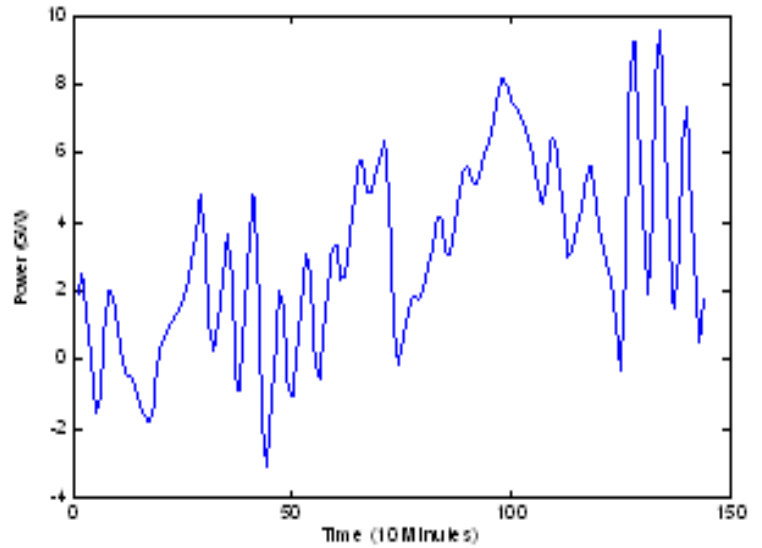

Figure 2. 10-minute balancing requirements of WECC on 1st of January

In Fig.3 the load profile versus hourly LMP of WECC on 1 st of January is depicted. The peak load of the day given in the solid blue line takes place at $7 \mathrm{pm}$ priced by the highest value of LMP as shown in the dotted blue line. When the EES gets to perform load shifting, it can be found that the new load curve as given the red solid line has a lower peak value and a larger bottom value than the original load curve. By cutting the peak load, the cost of peak load hour is accordingly reduced as given in the red dotted line.

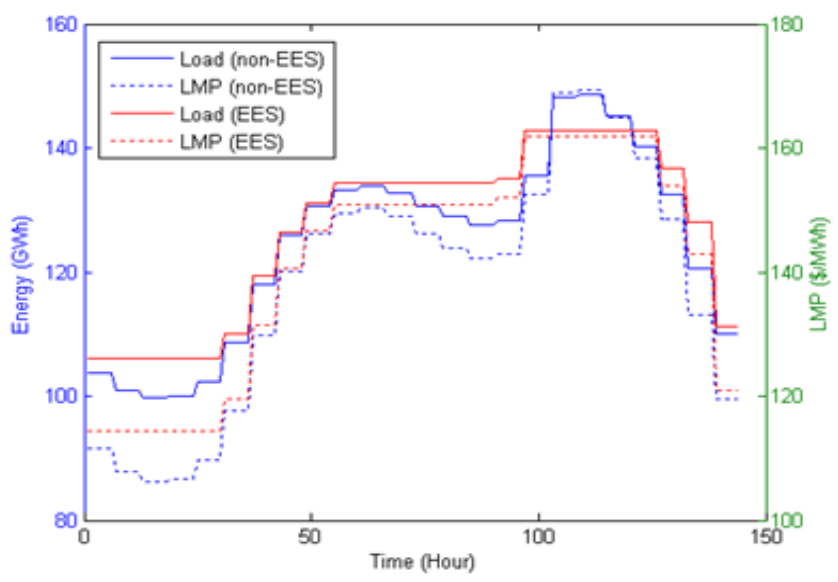

Figure 3. Load profile versus hourly LMP of WECC on $1^{\text {st }}$ of January

The energy storage level and the power flow of the EES are depicted in Fig. 4. It can be found that the battery is first charged since the early morning balancing requirements are down signals and the energy cost LMP is relatively low. After the 100th 10 minutes, the EES mainly discharges. This is due to the high up balancing signal coming at that moment and the preparation for the later action of peak load shaving. When the peak load moment arrives, the power discharged by EES is much reduced as curtailing the load requires the EES to be charged. However, due to the relatively high up balancing requirements, the EES still works in discharging mode in most of the time till the end of the day. 


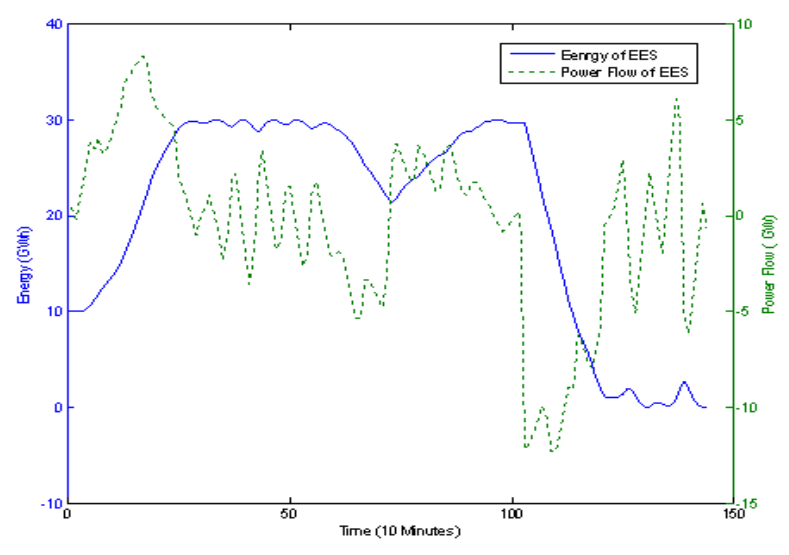

Figure 4. Energy storage level and power flow of the EES on $1^{\text {st }}$ of January

The economic performance of the EES on $1^{\text {st }}$ of January is given in Table II. It is found that the system cost is actually increased when having the EES to provide load shifting and balancing services. This is because on that day, the balancing signals are always up signals which require the EES to discharge. Even though there is energy initially stored in the EES, the EES still have to buy energy through load shifting service to meet the continuous up balancing requirements.

TABLE II. ECONOMIC PERFORMANCE OF EES ON $1^{\text {ST }}$ OF JANUARY

\begin{tabular}{|l|c|c|}
\hline & System(non-EES) & System $(\mathrm{EES})$ \\
\hline Load Cost $(\$ 1 \mathrm{M})$ & 420 & $437+1.2$ \\
\hline Balancing Cost $(\$ 1 \mathrm{M})$ & 3.2 & 0 \\
\hline Total Cost $(\$ 1 \mathrm{M})$ & 423.2 & 438.2 \\
\hline
\end{tabular}

\section{2) Case $2-14^{\text {th }}$ of August}

In Fig. 5, 10-minutes balancing signals are shown in the solid blue line. Compare to the balancing signals on $1^{\text {st }}$ of January, the signals on $14^{\text {th }}$ of August are not always up signals.

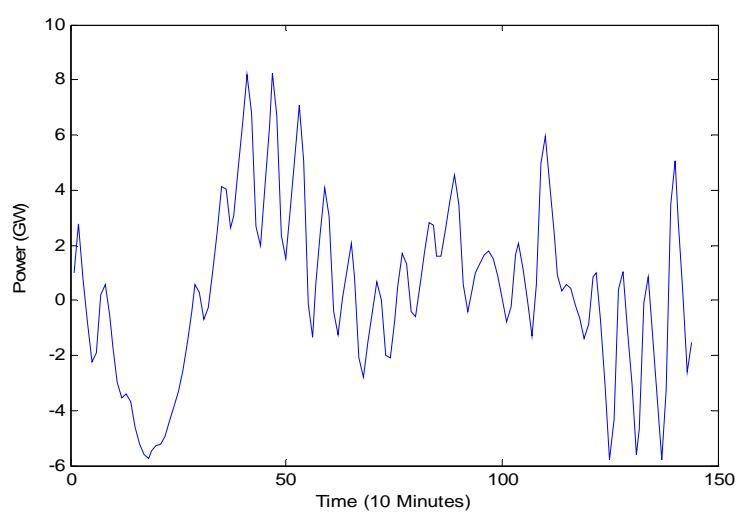

Figure 5. 10-minute balancing requirements of WECC on $14^{\text {th }}$ of August

The load profile versus hourly LMP of WECC on $14^{\text {th }}$ of August is given in Fig. 6. The peak load of the original load profile of the system without EES occurs at $5 \mathrm{pm}$. As the peak load is larger than $185 \mathrm{GW}$, the LMP for 5PM given in the blue dotted line is much higher than usual. The involvement of the EES successfully cut the peak load into a smaller value, resulting in a much lower LMP value for $5 \mathrm{pm}$.

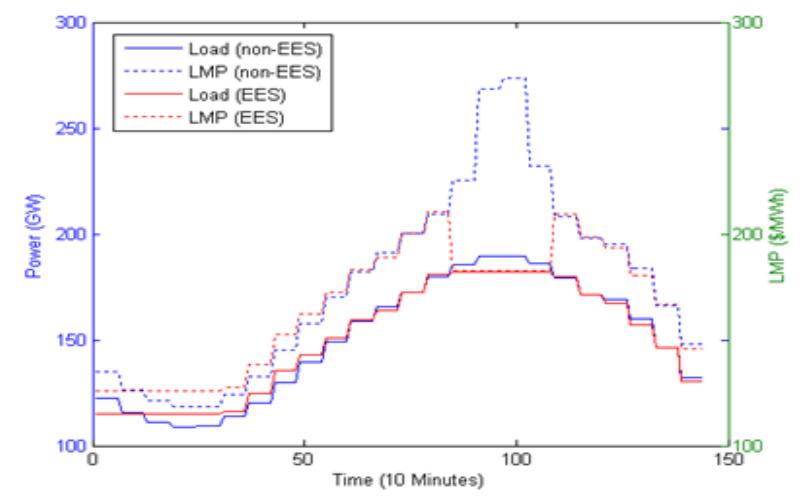

Figure 6. Load profile versus hourly LMP of WECC on $14^{\text {th }}$ of August

The energy storage level and the power flow of the EES on $14^{\text {th }}$ of August are depicted in Fig. 7. It is seen that the EES is first charged in the morning and then starts discharging when the peak load arrives. In the end of the day, the EES is completely empty in order to maximize the usage of its stored energy.

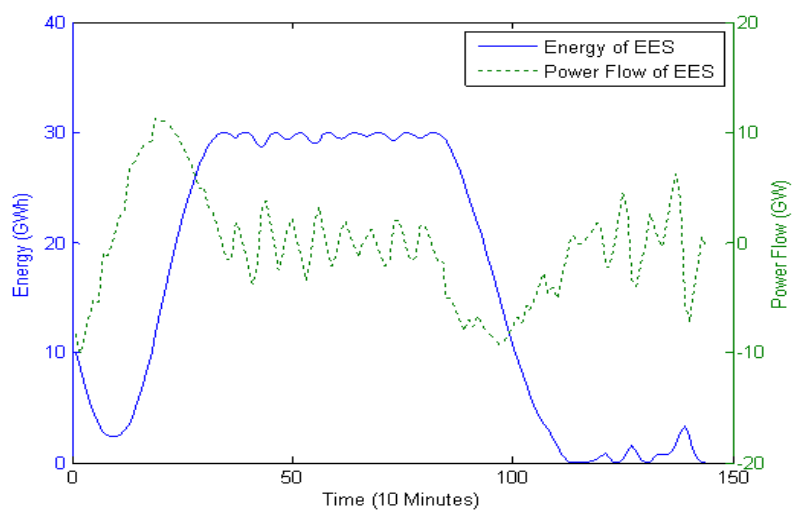

Figure 7. Energy storage level and power flow of the EES on $14^{\text {th }}$ of August

In Table III, the comparison of total cost between the system with EES and without EES is given. Since the balancing signal requires the EES to charge and discharge almost evenly, the EES does not need to buy more energy when it provides load shifting services. Further, the reduction of peak load results in a relatively low value of LMP, which in turn brings in some benefits. Due to such reasons, the total cost is reduced from 667.3million \$ down to 639.2 million \$.

TABLE III. ECONOMIC PERformance OF EES ON $14^{\mathrm{TH}}$ OF AUGUST

\begin{tabular}{|l|c|c|}
\hline & System(non-EES) & System (EES) \\
\hline Load Cost $(\$ 1 \mathrm{M})$ & 665 & $638+1.2$ \\
\hline Balancing Cost $(\$ 1 \mathrm{M})$ & 2.3 & 0 \\
\hline Total Cost $(\$ 1 \mathrm{M})$ & 667.3 & 639.2 \\
\hline Saving $(\$ 1 \mathrm{M})$ & \multicolumn{2}{|c|}{29.3} \\
\hline
\end{tabular}


3) Case 3 - Annual Economics of WECC system when the EES provides two services

Regarding the annual study, the optimization program for dispatching the EES is done on daily base due to the limited calculating resource. At the end of every day, the energy left in the EES is further assumed to be equal to the initial energy storage level $10 \mathrm{GWh}$ in order to guarantee there is enough power to meet continuous up balancing signals. The daily optimal dispatch is repeated for the whole year 2030. The annual cost performance is given in Fig. 8. The original cost for load serving and meeting balancing requirements are calculated for every month and depicted in blue bars and green bars, while the cost for meeting the load when the system includes EES is depicted by the red bars. Compared with the cost for meeting the hourly load, the balancing cost represents a small fraction of the original total cost. A summary of the annual cost for system with and without the EES is given in Table IV showing that the total savings by economically dispatch the EES for multi-service provision can yield 2570.46 million $\$$ in 2030.

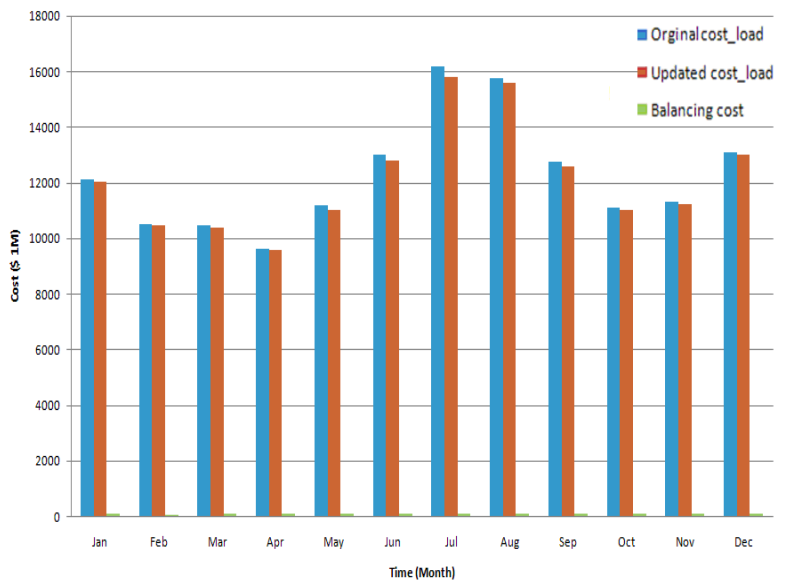

Figure 8. Annual cost performance for WECC system with the EES provides both load shifting and 10-minute balancing services for the year 2030

TABLE IV. AnNual EConomic Performance of EES

\begin{tabular}{|l|c|c|}
\hline & System(non-EES) & System (EES) \\
\hline Load Cost $(\$ 1 \mathrm{M})$ & 147058.83 & 145394.2 \\
\hline Balancing Cost $(\$ 1 \mathrm{M})$ & 905.83 & 0 \\
\hline Total Cost $(\$ 1 \mathrm{M})$ & 147964.66 & 145394.2 \\
\hline Saving $(\$ 1 \mathrm{M})$ & \multicolumn{2}{|c|}{2570.46} \\
\hline
\end{tabular}

4) Case 4 - Annual Economics of WECC system when the EES provides only load shifting

When the EES only provides load shifting service, it has more flexibility on changing the original load profile. One example showing such difference on 1st of January is given in Fig. 9. Same as in Fig. 3, the peak load of the original load profile depicted in blue is reduced when the EES provides both load shifting and 10-minute balancing services. In the case that the EES provides only load shifting, the peak load is reduced to an even lower value depicted by the green line. Energy consumption during the day is also reduced, as the EES is not needed to be charged to provide additional energy for up balancing purpose. The cost for meeting the updated load profile when the EES helps to shift the load is 414 million \$. By adding the balancing cost onto it, the total system cost for 1st of January is 417.2 million \$. Compared with the total costs under both cases given in Table II, using EES to provide load shifting only apparently yields more saving than to provide both load shifting and 10-minute balancing services.

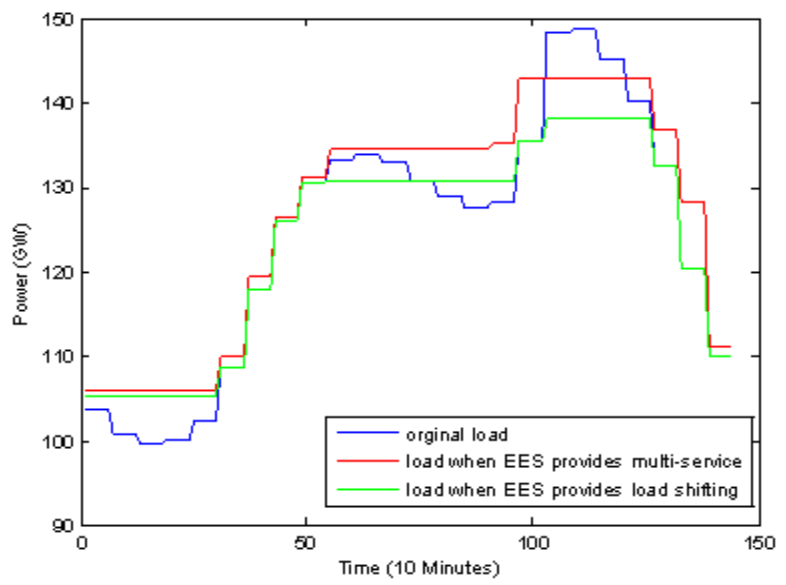

Figure 9. Comparison of load shifting capability of the EES between the system with multi-service provision and single service provision

Same annual economics calculation procedure carried out in Case 3 is applied to investigating the annual economics for the system using the EES to provide load shifting service only, and the annual cost for meeting the hourly load is found as 145079.66 million \$. Although this is less than the load cost given in the third column of Table IV, due to the additional balancing cost, the overall saving for this case is in fact less than the case when the EES is used to provide multi-services. In other words, using the assumed EES to provide both load shifting and balancing services for the 2030 WECC load scenario is more profitable than to provide either of the two required services.

\section{CONCLUSION}

This paper has presented a generic optimization model that explores the difficulty met by Electric Energy Storage (EES) systems when economic dispatch for multiple-service provision is at request. When such model is applied to solving the economic dispatch problem of using EES to provide both load shifting and 10-minute balancing services for one 2030 load scenario of WECC, the methodology takes into account the dynamics of the cost function which is represented by a nonlinear function of hourly load. Economic performance for the according energy system has been studied and analyzed. Results shows using the EES to provide load shifting and 10minute balancing service results in significant saving for the system operation. Although the economics of such study are very case sensitive, the method presented in this paper may be 
useful to evaluate the economics of EES and to optimally size the EES when specific power system information and service requirements are already defined.

\section{ACKNOWLEDGMENT}

The authors gratefully acknowledge the contributions of Michael C.W. Kintner-Meyer, Yousu Chen, Xinxin Guo, Shuai $\mathrm{Lu}$, all with the Energy Technology Development Group of PNNL, for valuable discussions and ideas.

\section{REFERENCES}

[1] B. B. Lundin, U. L. M, "Electricity Storage," EUSUSTEL project. Deliverable of Task 3.3.8 Work Package 3. [Online] Available: http://www.eusustel.be/public/documents publ/WP/WP3/EUSUSTEL\% 20WP3\%20Storage.pdf

[2] C.D. Parker, "Lead-acid battery energy storage systems for electricity supply networks," Journal of Power Sources, Nov. 2001.

[3] E. Zvingilaite, H.K. Jacobsen, "Overview of Optimal Market Response Options," RESPOND Report D5, une 2008, [Online] Available: http://www.ecn.nl/docs/library/report/2009/o09017.pdf
[4] C. Binding, D. Gantenbein, and P. B. Andersen, "Electricl Vehicle Fleet Integration in the Danish EDISON Project- A Virtual Power Plant on the Island of Bornholm, ". accepted and to be by PES General Meeting 2010, Minneapolis, Mn USA, July, 2010

[5] C.J. Greiner, M. Korpas, T. Gjengedal, "Optiaml Operation of Energy Storage Systems Combinded with Wind Power in Short-Term Power Markets,", proceedings of EWEC2009, Marseille, France, March, 2009

[6] E. D. Castronuovo and J.A. Lopes, "Optimal operation and hydro storage sizing of a wind-dydro power plant," Internal Journal of Electricl Power \& Energy Systems, vol. 26, iss. 10, December 2004, pp.771-778

[7] B. Lu and M. Shahidehpour, "Short-Term Scheduling of Battery in a Grid-connected PV/Battery System," IEEE Transaction on Power Systems, 2005, vol. 20, part 2, pp. 1053-1061

[8] C.H. Lo, M. Anderson, "Economic Dispatch and Optimal Sizing of Battery Energy Storage Systems in Utility Load-leveling Operations," IEEE Transaction on Energy Conversion, 1999, vol. 14, iss. 3, pp. 824829

[9] A. Oudalov, R. Cherkaoui, A. Beguin, "Sizing and Optimal Operation of Battery Energy Storage System for Peak Shaving Application,"Proceedings of Power Tech 2007, Lausanne, Switzerland, July, 2007

[10] PROMOD: http://www.ventyx.com/analytics/promod.asp

[11] Matlab Nonlinear Optimization Toolbox: http://www.mathworks.com/products/optimization/ 